\title{
Just and Well-Tempered Tuning
}

This table lists the just coordinates of the just tuning intervals (with respect to c, second tone in first column) according to Vogel [1089], see Section 7.2.1.4, together with the value in Cents, and the deviation in \% from the tempered tuning with 100, 200, 300, etc. Cents.

\begin{tabular}{|l|r|r|r|r|r|r|}
\hline $\begin{array}{l}\text { Tone } \\
\text { name }\end{array}$ & $\begin{array}{r}\text { Frequency } \\
\text { ratio }\end{array}$ & $\begin{array}{r}\text { Octave } \\
\text { coord. }\end{array}$ & $\begin{array}{r}\text { Fifth } \\
\text { coord. }\end{array}$ & $\begin{array}{r}\text { Third } \\
\text { coord. }\end{array}$ & $\begin{array}{r}\text { Pitch } \\
(C t)\end{array}$ & $\begin{array}{r}\% \\
\text { deviation }\end{array}$ \\
\hline \hline$c$ & 1 & 0 & 0 & 0 & 0 & 0 \\
\hline$d_{b}$ & $16 / 15$ & 4 & -1 & -1 & 111.73 & +11.73 \\
\hline$d$ & $9 / 8$ & -3 & 2 & 0 & 203.91 & +1.96 \\
\hline$e_{b}$ & $6 / 5$ & 1 & 1 & -1 & 315.65 & +5.22 \\
\hline$e$ & $5 / 4$ & -2 & 0 & 1 & 386.31 & -3.42 \\
\hline$f$ & $4 / 3$ & 2 & -1 & 0 & 498.05 & -0.39 \\
\hline$f_{\sharp}$ & $45 / 32$ & -5 & 2 & 1 & 590.22 & -1.63 \\
\hline$g$ & $3 / 2$ & -1 & 1 & 0 & 701.96 & +0.28 \\
\hline$a_{b}$ & $8 / 5$ & 3 & 0 & -1 & 813.69 & +1.71 \\
\hline$a$ & $5 / 3$ & 0 & -1 & 1 & 884.36 & -1.74 \\
\hline$b_{b}$ & $16 / 9$ & 4 & -2 & 0 & 996.09 & -0.39 \\
\hline$b$ & $15 / 8$ & -3 & 1 & 1 & 1088.27 & -1.07 \\
\hline
\end{tabular}

